Original Research

\title{
Technostress: how does it affect the productivity and life of an individual? Results of an observational study
}

\author{
Giuseppe La Torre*, Veronica De Leonardis, Marta Chiappetta \\ Department of Public Health and Infectious Diseases, Sapienza University of Rome, 00185, Rome, Italy
}

\section{A R T I C L E I N F O}

\section{Article history:}

Received 1 July 2020

Received in revised form

10 September 2020

Accepted 17 September 2020

Available online 6 November 2020

\section{Keywords:}

Technostress

Productivity

Life

Techno-stressors

Role stressors

\begin{abstract}
A B S T R A C T
Objectives: Technostress is an emergent phenomenon related to the pervasive use of technology and is associated with the increased computerisation and digitalisation seen over recent decades. This crosssectional observational study aims to investigate the impact that stress from the use of technologies (i.e. technostress) has on the productivity and life of an individual. Study design: Cross-sectional study.

Methods: Data were collected using a previously proposed and validated questionnaire. The questionnaire was translated into Italian and transformed into an online format with a Google Docs form. The questionnaire was then associated with a link and $\mathrm{QR}$ code (also available in paper format) and disseminated manually and through the use of e-mail and social networks, such as Facebook and Twitter. Results: The study sample included 313 individuals, $54.6 \%$ of whom were women. The mean age of the sample participants was 34.7 years. The dependent variables were technstressors (i.e. techno-overload, techno-invasion, techno-complexity, techno-insecurity and techno-uncertainty), role stressors (i.e. role overload and role conflict) and productivity. In the multivariate analysis, techno-overload was significantly associated with female gender $(\beta=0.128 ; P=0.018)$ and unemployment $(\beta=-0.303 ; P<0.001)$; techno-invasion was significantly associated with female gender $(\beta=0.098 ; P=0.081)$ and degree-level education $(\beta=0.149 ; P=0.008)$; techno-complexity was significantly associated with female gender $(\beta=0.107 ; P=0.057)$ and being married $(\beta=0.113 ; P=0.046)$; techno-uncertainty was significantly associated with unemployment $(\beta=0.337 ; P<0.001)$; role overload was significantly associated with female gender $(\beta=0.160 ; P=0.014)$ and productivity was significantly associated with degree-level education ( $\beta=0.125 ; P=0.057)$.

Conclusions: This observational study evaluated the phenomenon of both work-related and non-workrelated technostress of 313 individuals aged between 16 and 65 years. The present study investigated the impact of five techno-stressors, two role stressors and productivity. The results indicate that different techno-stressors are significantly associated with female gender, degree-level education and unemployment. Further research in this field is required to better understand and clarify the epidemiology, clinical presentation and determinants of technostress.
\end{abstract}

() 2020 The Royal Society for Public Health. Published by Elsevier Ltd. All rights reserved.

\section{Introduction}

Technostress is a condition of increasing interest due to the wide use of information and communication technologies (ICTs), both in the workplace and in private life. Although ICT has facilitated numerous work tasks, many clinical conditions related to their use,

\footnotetext{
* Corresponding author. Department of Public Health and Infectious Diseases, Sapienza University of Rome, Piazzale Aldo Moro 5, 00185, Rome, Italy. Tel.: +39 064454845.

E-mail address: giuseppe.latorre@uniroma1.it (G. La Torre).
}

such as technostress, have also emerged. Technostress is a psychophysiological state characterised by high levels of stresssensitive hormones, as well as cognitive symptoms, such as poor concentration, irritability and memory disorders. ${ }^{1}$ Similar to other types of stress, technostress appears to be characterised by the activation of the hypothalamus-hypophysis-adrenal gland axis, which causes an increase in the level of plasma cortisol. The factors, events and circumstances that lead to technostress are called 'techno-stressors', while antecedents are factors that can influence and amplify the effect of stressors on individuals. On the other hand, moderators (or inhibitors) can mitigate or inhibit the 
occurrence of technostress. Depending on the environment in which technostress develops, the condition can be considered as work related or non-work related, mainly determined by the problematic use of social networks (also known as social media addiction), which is a type of psychological or behavioural dependence on social media platforms. ${ }^{2}$

Work-related technostress has been more extensively studied because of its impact on productivity and business. There is evidence that information overload from the use of mobile phones can increase negative emotions, such as anger and anxiety in users, while the perceived utility of mobile phone devices attenuates this effect. ${ }^{3}$ Although a lot of research has been conducted on the biological effects of technostress, ${ }^{4,5}$ research on technostress and sociodemographic factors is limited. ${ }^{6,7}$ Thus, the objective of this study was to assess the association between sociodemographic variables and risk factors for technostress.

\section{Methods}

Data were collected using a questionnaire proposed and validated by Tarafdar et al. $^{8}$ The questionnaire was translated into Italian and back-translated into English to assess comparability and subsequently transformed into an online format with a Google Docs form. It was then associated with a link and QR code (also available in paper format) and disseminated through the use of email and social networks, such as Facebook and Twitter. The online questionnaire methodology enabled responses from a large number and wide variety of individuals. To be eligible for the study, respondents had to be aged between 16 and 65 years. The survey was available to complete for 9 months, from May 2018 to January 2019.

Among the risk factors for technostress (i.e. techno-stressors), the following eight variables were considered:

- techno-overload (i.e. the potential of ICT to drive an individual to work faster and longer), 5 items;

- techno-invasion (i.e. the potential of ICT to invade an individual's personal life), 4 items;

- techno-complexity (i.e. the inherent quality of an ICT that makes individuals feel inadequate with regard to their computer skills), 4 items;

- techno-insecurity (i.e. situations where users feel threatened about losing their jobs), 5 items;

- techno-uncertainty (i.e. constant upgrades of software and hardware that may impose stress on individuals), 4 items.

In addition, two role stressors (role overload and role conflict) and productivity were also considered among the dependent variables.

All eight dependent variables were measured using a five-point Likert scale ranging from 'strongly disagree' (1 point) to 'strongly agree' ( 5 points). For each variable, the mean value of all items was calculated.

Among possible confounding variables, age, gender and working activity were considered. These variables were selected because previous research suggests that they may impact how individuals perceive and use technology, as well as experience any stress associated with technology.,10

A non-probability snowball sampling method was used for recruiting participants. Although this leads to a non-random sample, the overall profile fits the gender composition of the Italian population recorded in 2018 (ISTAT).

Statistical analysis was carried out using frequency distribution, univariate and multivariate analysis. The reliability values for each subfactor were calculated using Cronbach's $\alpha$, and univariate analysis was conducted using the Student $t$-test. In terms of multivariate analysis, a linear regression model was built for each techno-stressor, using a stepwise approach (backward elimination). The goodness of fit of the model was assessed using $\mathrm{R}^{2}$. The analysis was carried out using SPSS, version 25.0. The statistical significance was set at $P<0.05$.

\section{Results}

The study sample consisted of 313 individuals: 171 women (54.6\%) and 142 men (45.4\%) (Table 1). The average age of the sample population was $34.7(+/-12.3)$ years. In terms of marital status, most respondents were single (70.3\%), followed by married (24.3\%). Regarding educational level, most respondents were degree graduates (55.6\%), with all remaining participants having high school qualifications (44.4\%). The working categories were represented by 92 (29.4\%) non-workers (e.g. students, unemployed and housewives) and 221 (70.6\%) workers (e.g. technicians, health professionals, researchers, telecommunications, teachers, employee, others). The average length of employment was 8.95 $(+/-11.5)$ years.

The dependent variables (measured using a five-point Likert scale ranging from 'strongly disagree' [ 1 point] to 'strongly agree' [5 points]) included five techno-stressors: techno-overload 2.5 (standard deviation $[\mathrm{SD}]=1.1$ ) (Cronbach's $\alpha=0.84$ ); technoinvasion 3.0 ( $\mathrm{SD}=1.1$ ) (Cronbach's $\alpha=0.78$ ); techno-complexity $2.4(\mathrm{SD}=1.1)$ (Cronbach's $\alpha=0.81)$; techno-insecurity $2.4(\mathrm{SD}=$ 1) (Cronbach's $\alpha=0.82)$; techno-uncertainty $2.9(\mathrm{SD}=1.2$ ) (Cronbach's $\alpha=0.79$ ). Two role stressors were as follows: role overload 3.6 (SD =1) (Cronbach's $\alpha=0.77$ ) and role conflict 2.8

Table 1

Characteristics of the sample population.

\begin{tabular}{|c|c|}
\hline Variable & $\mathrm{N}(\%)$ or mean $(\mathrm{SD})$ \\
\hline \multicolumn{2}{|l|}{ Gender } \\
\hline Female & $171(54.6 \%)$ \\
\hline Male & $142(45.4 \%)$ \\
\hline Age in years & $34.73(12.33)$ \\
\hline \multicolumn{2}{|l|}{ Marital status } \\
\hline Married & $76(24.3 \%)$ \\
\hline Divorced & $15(4.8 \%)$ \\
\hline Single & $220(70.3 \%)$ \\
\hline Widow(er) & $2(0.6 \%)$ \\
\hline \multicolumn{2}{|l|}{ Educational level } \\
\hline High school & $139(44,4 \%)$ \\
\hline Degree & $174(55,6 \%)$ \\
\hline \multicolumn{2}{|l|}{ Job } \\
\hline Student/unemployed/housewife & $92(29.4 \%)$ \\
\hline Technical job & $45(14.4 \%)$ \\
\hline Health/research professional & $43(13.7 \%)$ \\
\hline Communication (blogger, journalist and so on) & $25(8.0 \%)$ \\
\hline Teacher & $11(3.5 \%)$ \\
\hline Employee & $46(14.7 \%)$ \\
\hline Other & $51(16.3 \%)$ \\
\hline Years of employment & $8.95(11.51)$ \\
\hline \multicolumn{2}{|l|}{ Dependent variable ${ }^{a}$} \\
\hline Techno-overload & $2.5(1.1)$ \\
\hline Techno-invasion & $3.0(1.1)$ \\
\hline Techno-complexity & $2.4(1.1)$ \\
\hline Techno-insecurity & $2.4(1)$ \\
\hline Techno-uncertainty & $2.9(1.2)$ \\
\hline Role overload & $3.6(1)$ \\
\hline Role conflict & $2.8(1.0)$ \\
\hline Productivity & $4.1(0.8)$ \\
\hline
\end{tabular}

SD, standard deviation.

a Measured using a five-point Likert scale ranging from 'strongly disagree' (1 point) to 'strongly agree' (5 points). 
( $\mathrm{SD}=1.0$ ) (Cronbach's $\alpha=0.78)$. The impact of technostress on productivity was also assessed: $4.1(\mathrm{SD}=0.8)$ (Cronbach's $\alpha=0.89$ ).

Univariate analysis of the five techno-stressors showed that techno-overload was significantly associated with gender $(2.8 \mathrm{fe}-$ males, 2.5 males; $P=0.010$ ), age group ( 2.6 in individuals aged $<30$ years, 2.8 in individuals aged $\geq 30$ years; $P=0.039$ ) and working activity ( 2.9 workers, 2.1 non-workers; $P<0.001$ ) (Table 2 ).

Techno-invasion was significantly associated with gender (3.2 females, 2.9 males; $P=0.041)$ and the educational level (2.8 nondegree, 3.2 degree level; $P=0.005$ ), while techno-complexity was significantly associated only with marital status (2.6 married, 2.3 non-married; $P=0.045$ ).

Techno-uncertainty was significantly associated with age (2.7 in individuals aged $<30$ years, 3.2 in individuals aged $\geq 30$ years; $P=0.001$ ), marital status (3.3 married, 2.8 non-married; $P=0.002$ ), working activity (3.2 workers, 2.3 non-workers; $P<0.001$ ) and years of employment $(2.7$ for employment $<10$ years, 3.4 for employment $\geq 10$ years; $P<0.001$ ). Techno-insecurity was not significantly associated with any of the confounding variables considered in this study.

In terms of the two role stressors, role overload was shown to be only significantly associated with gender (3.7 females, 3.4 males; $P=0.014)$, while role conflict was significantly associated with marital status (2.6 married, 2.9 non-married; $P=0.049$ ), working activity (2.7 workers, 3.4 non-workers; $P=0.003$ ) and years of employment ( 2.9 for employment $<10$ years, 2.6 for employment $\geq 10$ years; $P=0.017$ ). Productivity was only significantly associated with educational level (3.9 non-degree, 4.2 degree level; $P=0.033$ ).

Multivariate analysis (Table 3 ) confirmed results from the univariate analysis; techno-overload was significantly associated with female gender with a standardized beta coefficient $(\beta)$ of 0.128 $(P=0.018)$ and with unemployment $(\beta=-0.303 ; P<0.001)$; techno-invasion was significantly associated with female gender $(\beta=0.098 ; P=0.081)$ and degree-level education $(\beta=0.149$; $P=0.008)$; techno-complexity was significantly associated with female gender ( $\beta=0.107 ; P=0.057)$ and being married $(\beta=0.113$; $P=0.046)$; techno-uncertainty was significantly associated with unemployment $(\beta=0.337 ; P<0.001)$ and techno-insecurity was not associated with any of the considered explanatory variables.

Multivariate analysis of the two role stressors showed that role overload was only significantly associated with female gender $(\beta=0.160 ; P=0.014)$ and role conflict was only significantly associated with unemployment $(\beta=0.172 ; P=0.008$ ). Productivity was shown to be significantly associated with degree-level education $(\beta=0.125 ; P=0.057)$ and unemployment $(\beta=-0.113$; $P=0.084)$.

\section{Discussion}

Technostress is a recently emerging problem related to the increasing computerisation and digitisation seen in recent decades. This cross-sectional observational study aimed to assess the association between sociodemographic variables and risk factors for technostress.

ICTs have increasingly permeated both professional and personal lives, and their usefulness is undeniable. As a result, access to information is very quick and easy, and we can communicate with colleagues, friends and family at the same time. Despite the positive impacts of ICT, some negative effects have emerged from the use of technology.

Firstly, ICT has been shown to induce anxiety and tension in some users, a condition called techno-anxiety. ${ }^{11}$ For certain individuals, interaction with computers is characterised by nervousness and apprehension, which can have psychological consequences, such as insecurity about ICTs and decreased confidence and overall comfort regarding their use. Moreover, the extensive and compulsive use of the internet and smartphones can cause a condition of dependency called techno-addiction. ${ }^{12}$

Secondly, the use of ICTs has been shown by some authors to create stress in users (technostress), which is the central theme of the present study.

When an individual experiences stress, the body has an adaptive reaction in response to factors, called stressors, which alter homoeostasis. The short-term response to a stressor is generally

Table 2

Results of the univariate analysis [mean (SD)] ${ }^{\mathrm{a}, \mathrm{b}}$.

\begin{tabular}{|c|c|c|c|c|c|c|c|c|}
\hline Variable & Techno-overload & Techno-invasion & Techno-complexity & Techno-insecurity & Techno-uncertainty & Role overload & Role conflict & Productivity \\
\hline \multicolumn{9}{|l|}{ Gender } \\
\hline Female & $2.8(1.1)$ & $3.2(1.1)$ & $2.5(1.1)$ & $2.4(1)$ & $3.0(1.2)$ & $3.7(1)$ & $2.7(1.0)$ & $4.2(0.7)$ \\
\hline Male & $2.5(1.1)$ & $2.9(1.2)$ & $2.3(1.1)$ & $2.5(1)$ & $2.8(1.2)$ & $3.4(0.9)$ & $2.8(1.1)$ & $4.0(0.9)$ \\
\hline$P$-value & 0.010 & 0.041 & 0.056 & 0.880 & 0.116 & 0.014 & 0.755 & 0.123 \\
\hline \multicolumn{9}{|l|}{ Age } \\
\hline$<30 y$ & $2.6(1.2)$ & $3.0(1.0)$ & $2.3(1.1)$ & $2.4(0.9)$ & $2.7(1.2)$ & $3.6(0.9)$ & $2.9(1.0)$ & $4.1(0.8)$ \\
\hline$\geq 30 \mathrm{y}$ & $2.8(1.1)$ & $3.1(1.2)$ & $2.4(1.1)$ & $2.4(1.0)$ & $3.2(1.2)$ & $3.5(1)$ & $2.7(1.1)$ & $4.1(0.8)$ \\
\hline $\bar{P}$-value & 0.039 & 0.639 & 0.368 & 0.855 & 0.001 & 0.560 & 0.060 & 0.605 \\
\hline \multicolumn{9}{|l|}{ Marital status } \\
\hline Married & $2.8(1.2)$ & $3.1(1.2)$ & $2.6(1.1)$ & $2.5(1.1)$ & $3.3(1.2)$ & $3.7(0.9)$ & $2.6(1.1)$ & $4.1(0.9)$ \\
\hline Not married & $2.6(1.1)$ & $3.0(1.1)$ & $2.3(1.1)$ & $2.4(0.9)$ & $2.8(1.2)$ & $3.5(1)$ & $2.9(1.0)$ & $4.1(0.8)$ \\
\hline$P$-value & 0.203 & 0.829 & 0.045 & 0.469 & 0.002 & 0.318 & 0.049 & 0.626 \\
\hline \multicolumn{9}{|c|}{ Educational level } \\
\hline High school & $2.6(1.2)$ & $2.8(1.1)$ & $2.4(1.1)$ & $2.4(1)$ & $2.8(1.2)$ & $3.5(1.0)$ & $2.8(1.0)$ & $3.9(1)$ \\
\hline Degree & $2.8(1.1)$ & $3.2(1.0)$ & $2.4(1.1)$ & $2.5(1)$ & $3.0(1.2)$ & $3.6(0.9)$ & $2.7(1.1)$ & $4.2(0.7)$ \\
\hline$P$-value & 0.070 & 0.005 & 0.933 & 0.522 & 0.242 & 0.269 & 0.783 & 0.033 \\
\hline \multicolumn{9}{|l|}{ Job status } \\
\hline Employed & $2.9(1.1)$ & $3.1(1.1)$ & $2.4(1.1)$ & $2.4(1)$ & $3.2(1.1)$ & $3.5(1)$ & $2.7(1.0)$ & $4.1(0.8)$ \\
\hline Unemployed & $2.1(1.2)$ & $2.9(1.1)$ & $2.3(1.0)$ & $2.4(1)$ & $2.3(1.1)$ & $3.7(0.9)$ & $3.4(0.8)$ & $3.8(0.9)$ \\
\hline$P$-value & $<0.001$ & 0.086 & 0.442 & 0.832 & $<0.001$ & 0.380 & 0.003 & 0.065 \\
\hline \multicolumn{9}{|c|}{ Years of employment } \\
\hline$<10$ & $2.6(1.1)$ & $3.0(1.1)$ & $2.3(1.1)$ & $2.4(0.9)$ & $2.7(1.2)$ & $3.6(0.9)$ & $2.9(1)$ & $4.1(0.8)$ \\
\hline$\geq 10$ & $2.8(1.2)$ & $3.1(1.2)$ & $2.5(1.2)$ & $2.4(1.1)$ & $3.4(1.2)$ & $3.5(1)$ & $2.6(1.1)$ & $4.1(0.9)$ \\
\hline $\bar{P}$-value & 0.158 & 0.666 & 0.112 & 0.930 & $<0.001$ & 0.687 & 0.017 & 0.572 \\
\hline
\end{tabular}

SD, standard deviation.

a Measured using a five-point Likert scale ranging from ‘strongly disagree' ( 1 point) to 'strongly agree' (5 points).

b Bold indicates significant association. 
Table 3

Results of the multivariate analysis $[\beta(P$-value $)]$.

\begin{tabular}{|c|c|c|c|c|c|c|c|c|}
\hline Variable & Techno-overload & Techno-invasion & Techno-complexity & Techno-insecurity & Techno-uncertainty & Role overload & Role conflict & Productivity \\
\hline \multicolumn{9}{|l|}{ Gender } \\
\hline Female & $0.128(0.018)$ & $0.098(0.081)$ & $0.107(0.057)$ & - & - & $0.160(0.014)$ & - & - \\
\hline \multicolumn{9}{|l|}{ Age } \\
\hline $\begin{array}{l}<30 \mathrm{y} \\
\geq 30 \mathrm{y}\end{array}$ & - & - & - & - & - & - & - & - \\
\hline \multicolumn{9}{|l|}{ Marital status } \\
\hline Married & - & - & $0.113(0.046)$ & - & - & - & - & - \\
\hline \multicolumn{9}{|l|}{ Educational level } \\
\hline Degree & - & $0.149(0.008)$ & - & - & - & - & - & $0.125(0.057)$ \\
\hline \multicolumn{9}{|l|}{ Job status } \\
\hline Unemployed & $-0.303(<0.001)$ & - & - & - & $0.337(<0.001)$ & - & $0.172(0.008)$ & $-0.113(0.084)$ \\
\hline $\mathrm{R}^{2}$ of the model & 0.113 & 0.035 & 0.024 & & 0.114 & 0.026 & 0.030 & 0.034 \\
\hline
\end{tabular}

beneficial and represents a resilience mechanism in healthy individuals; however, this response is very different to chronic longterm stress, which may be associated with pathological effects. ${ }^{13}$

Technostress is a long-term pathological reaction to ICT stress that can occur in some individuals. Therefore, in the current 'Digital Age', knowledge of technostress is essential so that prevention programmes can be implemented, both in and out of the workplace.

The present study showed that three techno-stressors (technooverload, techno-invasion and techno-complexity) and role overload were more frequently experienced in women than in men. However, these results are in contrast with those presented by Riedl et al. ${ }^{14}$ because, similar to other types of stress, technostress also seems to be characterised by the activation of the hypothalamus-hypophysis-adrenal gland axis, which causes an increase in the level of cortisol in the blood. A laboratory experiment conducted by Riedl et al. ${ }^{14}$ showed that the salivary cortisol levels of a treatment group increased significantly after a system breakdown (which was the stressor) compared with a control group.

In a subsequent experiment performed by the same authors, the skin conductance of individuals was measured before and after a computer breakdown and during the execution of a task in a timepressured (treatment group) or non-time-pressured (control group) environment. Skin conductance was measured because it reflects the activation of the sympathetic division of the autonomic nervous system. In the treatment group, there was a significant increase in skin conductance after the stress stimulus, particularly in men compared with women. These findings support the hypothesis that a stressor activates the sympathetic nervous system and that men may be more susceptible to experiencing stress. ${ }^{15}$ In addition, Ragu-Nathan et al. ${ }^{10}$ showed, in a large cross-sectional study, that men experienced more technostress than women. Moreover, among the consequences of technostress that have been described among employees, antisocial behaviour on computers can impact men more than women; ${ }^{16}$ this is also in contrast with the present study. Instead, techno-overload is experienced less in non-workers than workers, and non-workers experience technouncertainty significantly more. From analysis of the available scientific literature, no studies support or refute these results, but interesting conclusions have emerged concerning workers. In an experimental study, email usage was interrupted in a sample of information workers for 5 days. In the 'no mail' group, participants spent significantly longer in a document or program window and had a significantly lower mean frequency of window switches, with respect to baseline. Moreover, the authors measured the levels of stress in seven employees using heart rate variability (decreased heart rate variability corresponds with increased levels of stress) and found that participants experienced significantly less stress during the 'no mail' period with respect to baseline where they had email access. ${ }^{17}$ Furthermore, the importance of work overload and role ambiguity has been stressed by Ayyagary, ${ }^{18}$ while Weinert et al. ${ }^{19}$ found that work overload in teleworkers was the main influencing factor for exhaustion.

This study shows that individuals with degree-level education significantly perceive techno-invasion and experience an influence of the use of technology on productivity. A cross-sectional study conducted by Waizenegger et al. ${ }^{20}$ supports this result on technoinvasion. In their study, constant connectivity, which causes techno-invasion, is identified as one of the major causes of technostress among knowledge workers. ${ }^{20}$ The term 'knowledge worker' was first coined by Drucker ${ }^{21}$ in his book, The Landmarks of Tomorrow. Drucker ${ }^{21}$ defined knowledge workers as high-level workers who apply theoretical and analytical knowledge, acquired through formal training, to develop products and services. They include professionals in information technology fields, such as programmers, web designers, system analysts, technical writers and researchers. Knowledge workers also include pharmacists, public accountants, architects, engineers, doctors, scientists, lawyers, financial analysts and design thinkers. The difference between knowledge workers and other workers is that the former have the ability to solve complex problems or develop new products or services in their fields of expertise. According to this definition, the group of graduates may overlap with that of knowledge workers. In fact, the significant perception of techno-invasion could be linked to the greater complexity of the activity carried out by the group of graduates.

This hypothesis is supported by a cross-sectional study in which it was found that task complexity significantly influences the level of technostress. ${ }^{22}$ In contrast with these results, Ragu-Nathan et al. showed that technostress decreased as education increased. ${ }^{10}$

The results of the present study on productivity are supported by a study in which work productivity seems to be negatively impacted by technostress. Tarafdar et al. showed that productivity and technostress are inversely related; in fact, a survey conducted on employees who use mobile phones routinely in their work showed that techno-stressors had a negative effect on productivity. ${ }^{8}$ Furthermore, in a narrative review by Tarafdar et al., ${ }^{24,25}$ it was shown that the same characteristics that make ICT useful (e.g. reliability, portability, user-friendliness and fast processing) may also undermine employee productivity, innovation and well-being.

In terms of marital status, married individuals experienced techno-complexity significantly more than non-married individuals. In addition, techno-insecurity is not significantly associated with any of the variables considered in this study and therefore was not perceived significant by any category. These results are not supported or refuted by other studies in the scientific literature. 
A significant association between age and technostress was not found in the present study, which is in contrast to several studies in the scientific literature. For example, in a well-conducted crosssectional study investigating work-related technostress, age had a significant positive relationship with technostress levels; thus, the older the individual, the higher the technostress level. ${ }^{26}$ One study showed that non-work-related technostress was lower for users aged $\geq 26$ years. ${ }^{27}$ Another study in older adults (aged $>60$ years) showed that higher levels of technostress were significantly associated with lower life satisfaction. ${ }^{28}$

It is important to recognise that job satisfaction at work is related to job performance. In Finland, Böckerman and Ilmakunnas $^{29}$ found that a one SD improvement in job satisfaction improved productivity by almost $7 \%$.

Our results are in line with those reported in a recent systematic review conducted by Berg-Beckhoff et al., ${ }^{7}$ who showed no linear trends between age and technostress.

There are several limitations to this study. First, the nonprobabilistic sampling method limits the generalisability of our findings; however, this sampling method did allow the survey to be conducted in a much more cost- and time-effective way. The sample size of the study could be considered relatively small, but this is, to our knowledge, the first survey on this issue in Italy. Although caution should be taken in interpreting the results, interesting insights can be derived from this research.

Burnout, depression, anxiety and perceived social pressure to be constantly available or connected are the most common psychological consequences of technostress. As a result of these health consequences, technostress should be included in the document related to the assessment of work-related risk according to the Consolidated Italian Law 81/2008 of Health and Safety at work in all workplaces where digital technologies are frequently used. Moreover, given the recent concerns surrounding technostress, the recognition of this stress condition and risk assessment in the workplace are essential to implement adequate protection and prevention measures, such as increased training of employees, as well as the implementation of specific symptom management strategies. $^{30-32}$ Recently, the approach of Positive Technology has been introduced in the context of the occupational medicine as a proactive solution for organisations that want to improve the wellbeing of their employees and prevent technostress. ${ }^{33}$

In conclusion, from a public health perspective, it is important to note that ICT use can be the cause of, or at least be associated with, technostress. This, in turn, is directly related to intensity of teleworking and consequently to work exhaustion. ${ }^{34}$ These issues need to be addressed as a high priority in times of smart working and teleworking. From a general point of view, technostress has a huge impact on life satisfaction. In addition, all the efforts to prevent or mitigate technostress need to be reinforced through involvement, literacy and technical support.

Further research in this field is required to better understand and clarify the epidemiology, clinical presentation and determinants of technostress.

\section{Author statements}

\section{Ethical approval}

This survey was approved by the Ethics Committee of the Sapienza University of Rome (ref. 19.4.2018).

\section{Funding}

None declared.

\section{Competing interests}

None declared.

\section{References}

1. Arnetz BB, Wiholm C. Technological stress: psychophysiological symptoms in modern offices. J Psychosom Res 1997;43(1):35-42. https://doi.org/10.1016/ S0022-3999(97)00083-4.

2. Griffiths M, Kuss D, Kuss DJ, Griffiths MD. Social networking sites and addiction: ten lessons learned. Int J Environ Res Publ Health 2017;14(3):311.

3. Lee J. Does stress from cell phone use increase negative emotions at work? Soc Behav Pers 2016;44(5):705-16. https://doi.org/10.2224/sbp.2016.44.5.705.

4. Friedman EH. Neurobiology of techno-stress. J Occup Med 1993 Mar;35(3):315.

5. Riedle R. On the biology of technostress: literature review and research agenda. In: ACM SIGMIS database: the DATABASE for advances in information systems; November 2012. available at, https://dl.acm.org/doi/10.1145/2436239. 2436242.

6. Hauk N, Göritz AS, Krumm S. The mediating role of coping behavior on the agetechnostress relationship: a longitudinal multilevel mediation model. PloS One 2019;14(3):e0213349.

7. Berg-Beckhoff G, Nielsen G, Ladekjær Larsen E. Use of information communication technology and stress, burnout, and mental health in older, middleaged, and younger workers - results from a systematic review. Int J Occup Environ Health 2017;23(2):160-71.

8. Tarafdar M, Tu Q, Ragu-Nathan BS, Ragu-Nathan TS. The impact of technostress on role stress and productivity. J Manag Inf Syst 2007;24(1):301-28. https:// doi.org/10.2753/MIS0742-1222240109.

9. Tarafdar M, Cooper CL, Stich J-F. The technostress trifecta - techno eustress, techno distress and design: theoretical directions and an agenda for research. Inf Syst J 2019;29:6-42. https://doi.org/10.1111/isj.12169.

10. Ragu-Nathan TS, Tarafdar M, Ragu-Nathan BS. The consequences of technostress for end users in organizations: conceptual development and empirical validation. Inf Syst Res 2008;19(4):417-33. https://doi.org/10.1287/ isre.1070.0165.

11. Marcoulides GA Measuring computer anxiety: the computer anxiety scale. Educ Psychol Meas 1989;49(3):733-9. https://doi.org/10.1177/ 001316448904900328

12. Young KS. The evolution of Internet addiction. Addict Behav 2017;64:229-30. https://doi.org/10.1016/j.addbeh.2015.05.016.

13. Romero LM, Platts SH, Schoech SJ, Wadaet H, Crespi E, Martin LB, et al. Understanding stress in the healthy animal-potential paths for progress. Stress 2015;18(5):491-7. https://doi.org/10.3109/10253890.2015.1073255.

14. Riedl R, Kindermann H, Auinger A, Javor A. Technostress from a neurobiological perspective: system breakdown increases the stress hormone cortisol in computer users. Bus Inf Syst Eng 2012;2:61-9. https://doi.org/10.1007/s12599012-0207-7.

15. Riedl R, Kindermann H, Auinger A, Javor A. Computer breakdown as a stress factor during task completion under time pressure: identifying gender differences based on skin conductance. Adv Hum Comput Interaction 2013;2013:1-8. https://doi.org/10.1155/2013/420169.

16. Kasuga N, Itoh K, Oishi S, Nagashima T. Study on relationship between technostress and antisocial behavior on computers. IEICE Trans Info Syst 2004;E87D(6): $1461-5$

17. Mark GJ, Voida S, Cardello AV. A pace not dictated by electrons: an empirical study of work without email. In: Proceedings of the SIGCHI conference on human factors in computing systems (CHI '12). New York, NY, USA: Association for Computing Machinery; 2012. p. 555-64. https://doi.org/10.1145/ 2207676.2207754.

18. Ayyagari R. What and why of technostress: technology antecedents and implications. Dissertation. Clemson University; 2007.

19. Weinert C, Maier C, Laumer S, Weitzel T. Does teleworking negatively influence IT professionals? An empirical analysis of IT personnel's telework-enabled stress. Proceedings of the 52nd ACM conference on computers and people research. 2014. p. 139-47. https://doi.org/10.1145/2599990.2600011.

20. Waizenegger L, Remus U, Maier R. The social media trap-how knowledge workers learn to deal with constant social connectivity. 49th Hawaii international conference on system sciences. 2016. p. 2115-24. https://doi.org/10.1109/ HICSS.2016.267.

21. Drucker PF. The Landmarks of tomorrow. London: Heinemann; 1959.

22. Koo C, Wati Y. What factors do really influence the level of technostress in Organizations? An empirical study. In: Nguyen NT, et al., editors. New challenges for intelligent information. Berlin Heidelberg: Springer-Verlag; 2011. p. 339-48.

24. Tarafdar M, Pullins EB, Ragu-Nathan TS. Technostress: negative effect on performance and possible mitigations. Inf Syst J 2015;25:103-32. https://doi.org/ 10.1111 isj.12042.

25. Tarafdar M, D'Arcy J, Turel O, Gupta A. The dark side of information technology. Winter): MIT Sloan Management Review; 2015. p. 61-70.

26. Shu $\mathrm{O}$ Tu $\mathrm{Q}$, Wang $\mathrm{K}$. The impact of computer self-efficacy and technology dependence on computer-related technostress: a social cognitive theory perspective. Int J Hum Comput Interact 2011;27(10):923-39. https://doi.org/ 10.1080/10447318.2011.555313. 
27. Sahin YL, Çoklar AN. Social networking users' views on technology and the determination of technostress levels. Procedia Soc Behav Sci 2009;1:1437-42. https://doi.org/10.1016/j.sbspro.2009.01.253.

28. Nimrod G. Technostress: measuring a new threat to well-being in later life. Aging Ment Health 2017;31:1-8. https://doi.org/10.1080/ 13607863.2017 .1334037$.

29. Böckerman P, Ilmakunnas P. The job satisfaction-productivity nexus: a study using matched survey and register Data. ILR Review 2012;65(2):244-62.

30. Chiappetta M. The technostress: definition, symptoms and risk prevention. Senses Sci 2017;4(1):358-61. https://doi.org/10.14616/sands-2017-1-358361.
31. Di Frenna E. Tecnostress Le 10 cose da sapere per affrontare il rischio nel lavoro digitale e imparare a valutarlo. 2015. . [Accessed 30 August 2018].

32. Perciavalle M, Prunesti A. Offline è bello. Milano: Franco Angeli; 2016.

33. Brivio E, Gaudioso F, Vergine I, Mirizzi CR, Reina C, Stellari A, Galimberti C. Preventing technostress through positive technology. Front Psychol 2018;9: 2569.

34. Ortbach K, Köffer S, Niehaves B. How IT consumerization affects the stress level at work: a public sector case study (Conference Paper). In: Proceedings - pacific asia conference on information systems, PACIS 2013. 17th pacific asia conference on information systems. Jeju Island; South Korea: PACIS; 2013. 18 June 2013 through 22 June 2013; Code 111845. 